Article

\title{
Entropy-Based Fusion of Water Indices and DSM Derivatives for Automatic Water Surfaces Extraction and Flood Monitoring
}

\author{
Paramate Horkaew ${ }^{1, *}$ (D) and Supattra Puttinaovarat ${ }^{2}$ \\ 1 School of Computer Engineering, Institute of Engineering, Suranaree University of Technology, \\ Nakhon Ratchasima 30000, Thailand \\ 2 Faculty of Science and Industrial Technology, Prince of Songkla University, Surat Thani Campus, \\ Surat Thani 84000, Thailand; supattra.p@psu.ac.th \\ * Correspondence: phorkaew@sut.ac.th
}

Received: 17 August 2017; Accepted: 24 September 2017; Published: 27 September 2017

\begin{abstract}
Reliable water surface extraction is essential for river delineation and flood monitoring. Obtaining such information from fine resolution satellite imagery has attracted much interest for geographic and remote sensing applications. However, those images are often expensive and difficult to acquire. This study proposes a more cost-effective technique, employing freely available Landsat images. Despite its extensive spectrum and robust discrimination capability, Landsat data are normally of medium spatial resolution and, as such, fail to delineate smaller hydrological features. Based on Multivariate Mutual Information (MMI), the Landsat images were fused with Digital Surface Model (DSM) on the spatial domain. Each coinciding pixel would then contain not only rich indices but also intricate topographic attributes, derived from its respective sources. The proposed data fusion ensures robust, precise, and observer-invariable extraction of water surfaces and their branching, while eliminating spurious details. Its merit was demonstrated by effective discrimination of flooded regions from natural rivers for flood monitoring. The assessments we completed suggest improved extraction compared to traditional methods. Compared with manual digitizing, this method also exhibited promising consistency. Extraction using Dempster-Shafer fusion provided a $91.81 \%$ F-measure, $93.09 \%$ precision, $90.74 \%$ recall, and $98.25 \%$ accuracy, while using Majority Voting fusion resulted in an $84.91 \%$ F-measure, $75.44 \%$ precision, $97.37 \%$ recall, and $97.21 \%$ accuracy.
\end{abstract}

Keywords: water surfaces extraction; flood monitoring; water indices; DSM; mutual information

\section{Introduction}

Floods are one of the most frequently occurring disasters that cause tremendous mortality and devastation to personal property and communities [1], particularly in heavily populated urban areas [2] Due to the severe disruption caused by floods, flood investigation and monitoring by state officials is often belated and superficial. In addition, those endeavors would require immense financial and human resources. Current advances in remote sensing technology have enabled the use of satellite imaging for surveillance and damage assessment $[3,4]$. Due to the reflective properties of groundcover, differentiating water passages such as rivers, or permanent water [5] from flooded areas, or temporary water [6] has remained a challenge. This problem is typically addressed by discerning spatio-temporal changes in images acquired in series. Successful flood monitoring is completed by accurately discerning the river from other groundcovers.

Obtaining detailed information of the earth's surface, including manmade structures and terrain characteristics, fine satellite images have played a major part in automated geographical information 
systems (GIS). The amount of information obtained from GIS has been ever increasing. Several modalities, including GeoEye, SPOT (Satellites Pour l'Observation de la Terre), IKONOS, and THEOS (Thailand Earth Observation Satellite) have been found to be effective, for instance, in characterizing land use and land cover [7-9]. Nonetheless, their primary drawbacks are that their images are often expensive and difficult to acquire, with limited spatial extent, and sometimes covered with cloud. In addition, many studies have reported that, despite their great spatial resolution, their spectral resolution was found to be inadequate $[10,11]$. On the other hand, the middle spatial resolution Landsat satellite images, being freely available [12,13] and containing relatively higher spectral resolution [14], have been widely used in many GIS studies. The difference in their spatial resolution has been proven to be discernible, both synthetically [15] and empirically [16]. Nonetheless, in the context of water extraction [17-21], Landsat images have been a more cost-effective choice for supporting a wide range of applications [17-22].

Sentinel-2 is another, more superior, modality with a spatial resolution of 10 meters and is also freely available. Several studies have used Sentinel-2 for river classification and flood monitoring. Those techniques were either based on water indices [23-25] or objects [26], with a rather high accuracy of $93 \%$ and $90 \%$, respectively. Specifically, in Zhou et al. [25], Sentinel-2 was compared against Landsat 7 and 8 for water surface extraction. They reported that the accuracy obtained from Sentinel- 2 was second only to Landsat 8 and is thus a viable alternative. Thus far, the limitation agreed upon by all these studied is that satellite images were incapable of extracting narrower water passages.

Digital Surface Model (DSM) is a capable alternative for discriminating water from non-water areas and takes into account the heights of global surface covering objects such as buildings and trees. With this modality, water bodies are characterized as those with locally minimum and small (or zero) deviated heights. Due to this characteristic of DSM, some have suggested using it to separate water areas from land [27] and to separate flooded areas from those that are not [28]. Similar topographic assumptions have also been imposed on DEM. In particular, Gallant [29] demonstrated that flat or zero mean curvature elevations are consistent with those of water levels. A notable flaw in the curvature assumption is that it does not necessarily hold true for urban areas, where flat surfaces may be buildings, roads, or other man-made structures. Higher order statistics, such as local variance, could also be used to further differentiate leveled water from similar surfaces, but they are inevitably more prone to imaging noise.

By exploiting the benefits of both modalities while minimizing their respective drawbacks, we present a novel method for water extraction by integrating no-cost satellite images with DSM by using Multivariate Mutual Information (MMI) and data fusion. The ability of this method to be applied to flood management is highlighted by discerning temporary from permanent water in remotely sensed images. Temporary water is presumably a flooded area and could be monitored during the course of the event. The experiments we completed demonstrate that the proposed technique is superior to traditional methods in terms of both precision and robustness against noise. Most importantly, this method reliably delineated narrower water branches, with relatively high consistency, compared with manual digitizing from aerial images.

The remainder of this article is organized as follows. The literature review section summarizes imaging and topographic data involved in this study, as well as relevant water surface extraction methods. We introduce theoretical backgrounds on the key elements of this study, including multidimensional mutual information and data fusion. Subsequently, the methodology section first outlines the proposed scheme, followed by its implementation. To highlight the merit and to demonstrate the potential of the proposed scheme, both the visual and numerical assessments are detailed in the results section. Lastly, the prospective areas for application of this method and areas of consideration are discussed. 


\section{Materials}

This section discusses literature related to developments in water surface extraction, involving data (Landsat and DSM), their interpretation (water indices), information theoretic similarity measure (MMI), and fusion techniques.

\subsection{Landsat Images}

Landsat images are a middle-range spatial resolution satellite images, usually analyzed in land use and land cover studies. The image resolution varies by Landsat sensor. For Landsat 8, the spatial resolution is $30 \mathrm{~m}$ for all bands, except for TIR and panchromatic bands, whose spatial resolutions are $100 \mathrm{~m}$ and $15 \mathrm{~m}$, respectively. In addition, various Landsat modalities have been used in the extraction and delineation of water surfaces. For example, Landsat Enhanced Thematic Mapper Plus (ETM+) [19-21], Landsat 5 [16], Landsat Thematic Mapper (TM) and ETM+ [17], and Multi-temporal Landsat [30,31], have been used as the tools to extract water surfaces, characterize their features, and detect their changes. Despite its advantages [12-14], Landsat's main drawback is that its images have limited spatial resolution [22,27-32]. For the extraction of finer hydrological details, Landsat could benefit from incorporating topographical features.

\subsection{Digital Surface Model (DSM)}

DSM encodes topographic height in its values, similar to the Digital Terrain Model (DTM), but the data are stored in raster form and include features above ground, such as buildings and vegetation, which helps differentiate elements augmented in DEM for observations. The spatial resolution of DSM is typically as high as five meters. This model has been used in a wide range of applications, such as building extraction [33,34], building change detection [35], and land cover classification [36]. Only been a few studies have investigated its potential as a water surface identifier, since the model was not developed for hydrological data. These studies involved the classification of water areas during flood events based on RADARSAT-1 and DSM [37] and the estimation of water surface elevation in inundated area using MODIS [38].

Several studies have made inferences from DSM geometric properties. One assumption was based on its local statistics. Specifically, standing water is a leveled surface and thus has a low standard deviation. Recent work [27] used this quality of water to separate it from a coal pile field and a coal gangue pile from GeoEye images using the Normalized Difference Water Index (NDWI). In this case, the standard deviation of surface heights was used as an auxiliary. However, the details of the extracted water bodies depend on the domain's spatial resolution where NDWI was computed, rendering their method unsuitable for medium spatial resolution satellite images.

The curvature represents the rate of change in surface orientation of a variable across an area. It has been widely applied in several remote sensing applications, including distinguishing buildings from forest areas [39], detecting landslide with average curvature among other attributes [40], assessing soil erosion [41], and extracting channel network from DEM [42]. This feature is also often used to describe the physical characteristics, such as convexity, concavity, and flatness, of an area $[43,44]$.

\subsection{Water Index}

The water index has been used to extract water surfaces from Landsat images. By exploiting its multispectral nature [31,45], the algebraic rational of different reflective bands has prevailed over any other single-band indicator. Several indices have been proposed in the literature, including the Normalized Difference Water Index (NDWI) [46-49], Normalized Difference Water Index 2 (NDWI2) [20,21,45-47], Modified Normalized Difference Water Index (MNDWI) [17-21,50-52], and the Normalized Difference Pond Index (NDPI) [52-56]. MNDWI [19,45,57] and NDWI2 perform equally well and generally better than the others. In the following experiments, both NDWI2 and MNDWI were chosen as the representative water indices. Notably, despite their success, MNDWI and NDWI2 
are incapable of delineating small hydrological features such as narrower canals and river branching. Moreover, in practice, their extraction is highly subjective, dependent upon user specified thresholds and their individual judgment.

\subsection{Mutual Information (MI)}

MI was founded on information theory and was later introduced to image registration $[58,59]$. MI measures the amount of information shared between two random variables, hypothetically originating from the same entity but not necessarily the same acquisition. In multi-spectral images, basic two-variable MI is inadequate, because, in some cases, a given pair of bands may lack sufficient similarity. Therefore, in imaging applications involving multiple modalities, opportunity exists to improve registration by adopting Multivariate Mutual Information (MMI). MMI has been widely applied in registering medical images [60-62], satellite images [63-66], and images in general [67]. In addition to apparent benefits, MMI has also been used in pattern recognition for feature selection [68] and classification [69]. Particularly in remote sensing, spatio-temporal analysis based on the MI of multi-band images has been proposed to detect change [70-72] and to monitor glaciers [73]. These studies reached their objective by maximizing the MI of two variables, $\mathrm{A}$ and $\mathrm{B}$, i.e.,

$$
\mathrm{I}(\mathrm{A}, \mathrm{B})=\mathrm{H}(\mathrm{A})+\mathrm{H}(\mathrm{B})-\mathrm{H}(\mathrm{A}, \mathrm{B})
$$

where $\mathrm{H}(\mathrm{A})$ and $\mathrm{H}(\mathrm{B})$ are the entropies of the respective variables, while $\mathrm{H}(\mathrm{A}, \mathrm{B})$ is their joint entropy. Since multiple thematic layers were considered in this study, we decided to use the MMI of four variables previously extended by Clark et al. [74]. This four-dimensional (4D) MI was expressed as that interaction information among $\mathrm{X} 1, \mathrm{X} 2, \mathrm{X} 3$, and $\mathrm{X} 4$, that is:

$$
\begin{gathered}
\mathrm{I}(\mathrm{X} 1 ; \mathrm{X} 2 ; \mathrm{X} 3 ; \mathrm{X} 4)=[\mathrm{H}(\mathrm{X} 1)+\mathrm{H}(\mathrm{X} 2)+\mathrm{H}(\mathrm{X} 3)+\mathrm{H}(\mathrm{X} 4)]- \\
{[\mathrm{H}(\mathrm{X} 1, \mathrm{X} 2)+\mathrm{H}(\mathrm{X} 1, \mathrm{X} 3)+\mathrm{H}(\mathrm{X} 1, \mathrm{X} 4)]+} \\
\mathrm{H}(\mathrm{X} 2, \mathrm{X} 3)+\mathrm{H}(\mathrm{X} 2, \mathrm{X} 4)+\mathrm{H}(\mathrm{X} 3, \mathrm{X} 4)]+ \\
{[\mathrm{H}(\mathrm{X} 1, \mathrm{X} 2, \mathrm{X} 3)+\mathrm{H}(\mathrm{X} 1, \mathrm{X} 2, \mathrm{X} 4)+\mathrm{H}(\mathrm{X} 1, \mathrm{X} 3, \mathrm{X} 4)+\mathrm{H}(\mathrm{X} 2, \mathrm{X} 3, \mathrm{X} 4)]-} \\
\mathrm{H}(\mathrm{X} 1, \mathrm{X} 2, \mathrm{X} 3, \mathrm{X} 4)]
\end{gathered}
$$

\subsection{Data Fusion}

Different remotely sensed thematic layers may be fused to enhance various analytical aspects of a study in terms of recognition, identification, detection, classification, and change detection [75]. These studies reported that data fusion yielded better results than relying solely on any single source of information. Moreover, uncertainty and misalignment are reduced by reciprocal adjustment. A number of fusion algorithms have been proposed in the literature [76-79]. Despite a variety of choices, the remote sensing community has favored Majority Voting and Dempster-Shafer, since their performance for extraction and classification is generally superior to others [80-82]. Hence, these algorithms were chosen in the current study.

Majority voting is the simplest way of combining results from different sources [83]. With this method, every result can cast one vote for the value it observed and the final result is then decided by that casted by the majority. This method has been used to detect change in urban areas [75] and combine textured images classifiers [84]. Dempster-Shafer is another fusion method [85,86]. It has been used in building extraction based on three thematic sources: DSM, results of the K-means clustering, and building outlines [34]. Fundamentally, it combines different datasets based on the degree of confidence related to a belief function of each class label. This belief function consists of two parameters: support or belief (Sup/Bel) and plausibility (Pls). The Dempster-Shafer method involves three steps. Firstly, it calculates mass functions, m, obtained from the class probability:

$$
m(\theta)=\sum_{A \subset 2^{\theta}} m(A)=1
$$


where $\theta$ is a frame of discernment, and $i$ contains two possible mutually exclusive and exhaustive states of a given pixel, i.e., $\{$ water, non-water $\}$, and $\mathrm{m}(\varnothing)=0$.

According to Trinder and Salah [81] and Rashidi and Ghassemian [82], $2^{\theta}$ is a power set, listing all possible subsets $\mathrm{A}$ of $\theta$, including an empty set, which is an undefined pixel. The mass $m(A)$, of a subset $\mathrm{A}$, is a proportion of the relevant and available evidence. It is given by basic probability assignment (BPA) of a random variable drawn from the distribution of respective data sources, i.e., water indices or local standard deviations (LSD) of topographic properties.

Secondly, the two parameters associated with each class $A \in 2^{\theta}$ were computed as follows:

$$
\begin{gathered}
\operatorname{Sup}(A)=\sum_{A_{i} \subset A} m\left(A_{i}\right) \\
\operatorname{Pls}(A)=\sum_{A_{i} \cap A \neq \varnothing} m\left(A_{i}\right)
\end{gathered}
$$

Finally, the fused mass function considering all the data sets is given by:

$$
m(A)=\frac{\sum_{A_{1} \cap A_{2} \ldots \cap A_{p}} \sum_{1 \leq n \leq p} m\left(A_{i}\right)}{1-K}
$$

where $K=\sum_{A_{1} \cap A_{2} \ldots \cap A_{p} \neq \varnothing} \sum_{1 \leq n \leq p} m\left(A_{i}\right)$, and $m\left(A_{i}\right)$ is the probability mass for class $A_{i}$ in the $n$th instance, out of 1 to $p$ results.

\section{Methodology}

Water extraction by means of traditional machine learning is based primarily on reflective water indices. Without other supportive indicators, the machine learning is occasionally unable to differentiate water bodies from other ambiguities such as built-up areas, land, manmade structures, and shadow or acquisition noises. Despite the state of the art noise filters, existing studies concur that all-around indices and their optimal ranges that can extract nothing but water have yet to be devised. Should such water indices be available, typical Landsat images would nonetheless contain insufficient details to reveal subtle hydrological features. Although Landsat images have successfully been used in a wide range of applications, their main pitfall is their merely medium spatial resolution. Even if the images could be interpolated to increase the spatial resolution, their intrinsic information is nonetheless incapable of extracting the narrower water bodies. A more realistic solution was to augment the spatial resolution by integrating DSM.

The aim of this study was to further improve water area classification, in terms of both accuracy and precision, from Landsat images by considering information mutually shared with topographic derivatives. To this end, the MMI of the NDWI2 and MNDWI water indices and local standard deviations (LSD) of height and curvature per the DSM data were optimized to determine suitable thresholds for respective attributes. The water surfaces, as observed from these tools, were then fused by means of majority voting and Dempster-Shafer methods. The extraction results from these decisions were subsequently validated against manual digitizing. This process is summarized in Figure 1. 


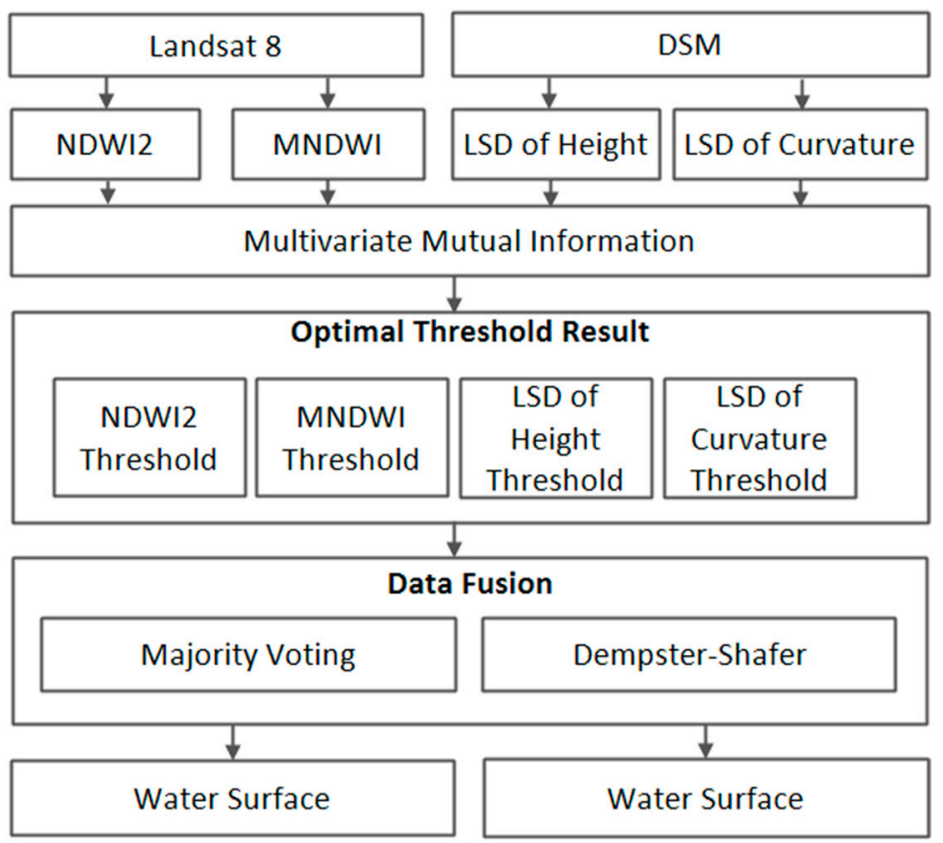

Figure 1. The proposed automated water surface extraction methodology.

\subsection{Data Preparation}

The following experiments involved four major cities in Thailand, with diverse climatic, residential, and geographical characteristics. They are: Pathumthani (Muang district: $1526 \mathrm{~km}^{2}$ ), Chumphon (Lang Suan district: $937 \mathrm{~km}^{2}$ ), Surat Thani (Muang district: $231 \mathrm{~km}^{2}$ ), and Nakhon Si Thammarat (Pak Phanang: $559 \mathrm{~km}^{2}$ ). They have all been subject to several major floods during the past decades. The most recent one occurred in January 2017 and severely affected the last three cities. Geographically, the cities are either on a plain, as is the case for Pathumthani, or on a peninsula-the remaining cities are surrounded by the Gulf of Thailand and the Andaman Sea. The major rivers considered in this study were Chao Phraya, Lang Suan, Tapi, and Pak Phanang, located in Pathumthani, Chumphon, Surat Thani, and Nakhon Si Thammarat, respectively. The DSM data at 5-meter spatial resolution were provided by the Department of Public Works and Town and Country Planning (DPWTCP), Pathumthani. The Landsat 8 images were downloaded from the United States Geological Survey (USGS) website. The modalities, acquisition date, and extraction type of the Landsat images are provided in Table 1. A total of 11 bands were taken from these images for layer stacking and then up-sampled to equal that of DSM, not in order to increase its intrinsic resolution, but so that pixel-wise fusion could be achieved. The ground reference was collected from manual digitizing of water surfaces from the corresponding aerial images, which were acquired from the Royal Thai Survey Department. Table 2 lists Landsat 8 bands' characteristics and Figure 2 shows interpolated images and derived water indices of a sampled area. 
Table 1. Detailed description of the Landsat images acquired in four cities in Thailand.

\begin{tabular}{cccc}
\hline Area & Data & Acquisition Date & Extraction Type \\
\hline \multirow{4}{*}{ Pathumthani } & Landsat 5 & 30 November 2011 & Temporary Water \\
& Landsat 5 & 6 September 2011 & Permanent Water \\
& Landsat 8 & 30 November 2013 & Permanent Water \\
& Landsat 8 & 2 February 2014 & Permanent Water \\
& Landsat 8 & 5 February 2015 & Permanent Water \\
\hline \multirow{2}{*}{ Chumphon } & Landsat 8 & 9 January 2017 & Temporary Water \\
& Landsat 8 & 18 February 2017 & Permanent Water \\
\hline \multirow{2}{*}{ Surat Thani } & Landsat 8 & 9 January 2017 & Temporary Water \\
& Landsat 8 & 18 February 2017 & Permanent Water \\
\hline \multirow{2}{*}{ Nakhon Si Thammarat } & Landsat 8 & 9 January 2017 & Temporary Water \\
& Landsat 8 & 18 February 2017 & Permanent Water \\
\hline \multirow{2}{*}{. }
\end{tabular}

Table 2. Landsat 8 wavelength characteristics.

\begin{tabular}{cccc}
\hline Landsat 8 Bands & Wavelength $(\mu \mathbf{m})$ & Landsat 8 Bands & Wavelength $(\mu \mathbf{m})$ \\
\hline Coastal/Aerosol & $0.435-0.451$ & SWIR-1 & $1.566-1.651$ \\
Blue & $0.452-0.512$ & SWIR-2 & $2.107-2.294$ \\
Green & $0.533-0.590$ & Pan & $0.503-0.676$ \\
Red & $0.636-0.679$ & Cirrus & $1.363-1.384$ \\
NIR & $0.851-0.879$ & TIR-1 & $10.60-11.19$ \\
& & TIR-2 & $11.50-12.51$ \\
\hline
\end{tabular}

Although Landsat contains 11 bands, this study required only Green, NIR, and SWIR-1 to compute NDWI2 (Green - NIR/Green + NIR) and MNDWI (Green - SWIR $1 /$ Green + SWIR 1 ). Although PAN correlates with NIR, its enhanced intrinsic spatial resolution was not sufficient to capture the details required and it was thus disregarded.
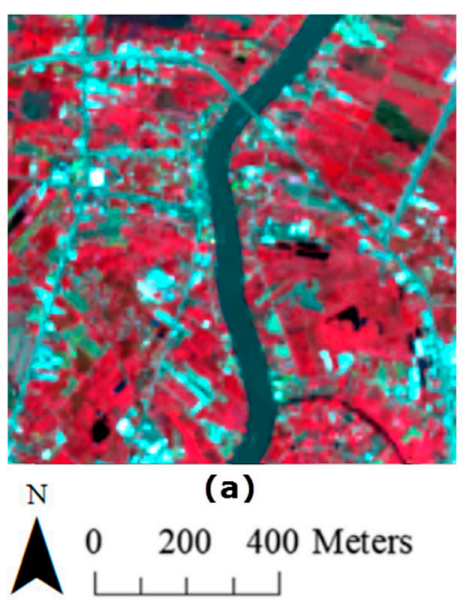

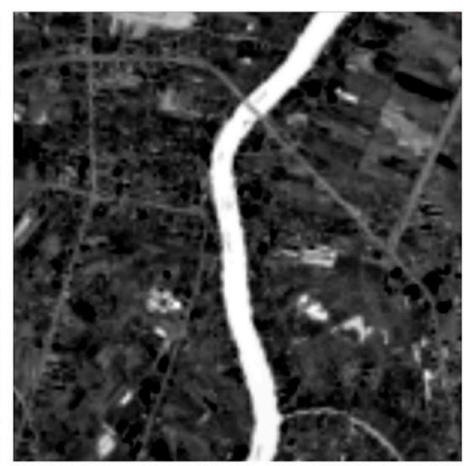

(b)

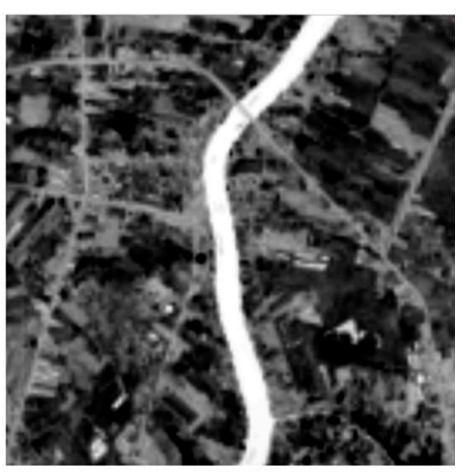

(c)

Figure 2. (a) Landsat 8 images interpolated at five-meter spatial resolution; and corresponding water index images: (b) MNDWI (Modified Normalized Difference Water Index); and (c) NDWI2 (Normalized Difference Water Index 2), of an area sampled in 2015.

\subsection{Extraction Based on Water Indices}

The NDWI2 and MNDWI were calculated from Landsat 8 images [48,51]. Normally, water surface extraction by using these indices would require empirical thresholds, by which water surface and build-ups are differentiated. Specifying suitable thresholds that precisely distinguish water pixels from other objects is a challenging task and remains actively investigated. Moreover, the values might only 
be accurate locally and not effective on a wider scale or applicable to different environments. In this study, no decision on an overall threshold was prescribed, but the values were adjusted adaptively according to underlying topographic contexts, with respect to their MMI.

\subsection{Extraction Based on Topographic Attributes}

\subsubsection{Local Standard Deviation of Surface Height}

Probable water pixels are those whose vicinities are relatively flat. This proposition was expressed as a LSD of a group of DSM pixels. In this study, the value was computed within a $3 \times 3$-pixel window centered at a corresponding pixel:

$$
\sigma_{i}=\sqrt{\frac{1}{8} \sum_{i=1}^{9}\left(D S M_{i}-\overline{D S M}\right)^{2}}
$$

where $\sigma_{i}$ is the standard deviation of an ith DSM pixel, whose height is $D S M_{i}$, and $\overline{D S M}$ is the mean height within a specified vicinity. The standard deviation close to zero is normally considered as belonging to water, while other types of land cover assume larger values. However, this study did not prescribe a threshold, but instead determined this value based on coupled relationships with reflectance and other topographic properties through MMI.

\subsubsection{Local Standard Deviation of Curvature in the DSM Process}

The curvature feature describes the convexity or concavity of a surface. The value can be positive, negative, or zero, representing concave, convex, and flat areas, respectively. For leveled water, this value is close to zero. The same may apply to any flat terrain. However, in DSM, water curvature appears to have a lower standard deviation. In this study, profile curvature was computed using Equation (8), based on a $3 \times 3$ neighborhood (Figure 3).

\begin{tabular}{|c|c|c|}
\hline $\mathrm{Z}_{1}$ & $\mathrm{Z}_{2}$ & $\mathrm{Z}_{3}$ \\
\hline $\mathrm{Z}_{4}$ & $\mathrm{Z}_{0}$ & $\mathrm{Z}_{5}$ \\
\hline $\mathrm{Z}_{6}$ & $\mathrm{Z}_{7}$ & $\mathrm{Z}_{8}$ \\
\hline
\end{tabular}

Figure 3. Pixel configuration used in the curvature calculation.

Provided c is a grid size, profile curvature $K$ of local surface is expressed by:

$$
K=\frac{-2\left(\mathrm{DG}^{2}+\mathrm{EH}^{2}+\mathrm{FGH}\right)}{\mathrm{G}^{2}+\mathrm{H}^{2}}
$$

where $\mathrm{D}=\left[\frac{\mathrm{z}_{4}+\mathrm{z}_{5}}{2-\mathrm{z}_{0}}\right] / \mathrm{c}^{2}, \mathrm{E}=\left[\frac{\mathrm{z}_{2}+\mathrm{z}_{7}}{2-\mathrm{z}_{0}}\right] / \mathrm{c}^{2}, \mathrm{~F}=\frac{\mathrm{z}_{3}-\mathrm{z}_{1}+\mathrm{z}_{6}-\mathrm{z}_{8}}{4 \mathrm{c}^{2}}, \mathrm{G}=\frac{\mathrm{z}_{5}-\mathrm{z}_{4}}{2 \mathrm{c}}$, and $\mathrm{H}=\frac{\mathrm{z}_{2}-\mathrm{z}_{7}}{2 \mathrm{c}}$.

The notations D-H were defined following Zeverbergen and Thorne [87], where D and E were second order partial derivatives of elevation ( $\mathrm{z}$ ) for $\mathrm{x}$ and $\mathrm{y}$, respectively; $\mathrm{F}$ was a second order mixed derivative for $\mathrm{x}$ and $\mathrm{y}$; and $\mathrm{G}$ and $\mathrm{H}$ were first order partial derivatives for $\mathrm{x}$ and $\mathrm{y}$, respectively. The local standard deviation of profile curvature was also derived according to Equation (7). Although an area with a value close to zero is normally assumed to be water, the optimal threshold was determined by using MMI. 


\subsubsection{Threshold Optimization Using Multivariate Mutual Information}

MMI is an information theoretical-based metric that measures the dependency of sensed data. In remote sensing, $\mathrm{MMI}$ is typically adopted as an objective function for spatially registering two or more relevant geographical acquisitions. However, as the thematic layers had already been registered in this study, MMI was used as an objective function for aligning layers, attributes, to determine the optimal thresholds and directions, using Equations (9) and (10). In the subsequent experiments, these layers were NDWI2 (X1), MNDWI (X2)), Local Standard Deviation (LSD) of Height Feature (X3), and LSD of curvature feature $(X 4)$.

$$
\begin{gathered}
\mathrm{T}_{\text {opt }}=\underset{\mathrm{T}}{\operatorname{argmax}}(\mathrm{MMI}(\mathrm{X} 1 ; \mathrm{X} 2 ; \mathrm{X} 3 ; \mathrm{X} 4)) \\
\mathrm{T}_{\text {opt }}=\underset{\mathrm{T}}{\operatorname{argmax}}(\mathrm{MMI}(\mathrm{X} 1 ; \mathrm{X} 2))
\end{gathered}
$$

Since addressing efficient optimization strategies and their parametric treatment fell outside of the scope of this study, the globally optimal thresholds set for these thematic layers were determined by exhaustive search across the plausible enclosing area. The resultant thresholds were accordingly used to extract water areas from respective layers.

\subsubsection{Data Fusion Between Segmented Satellite and DSM Images}

Although the segmented water bodies were accepted based on the mutual water hypothesis, sporadic ambiguities did exist in different layers. The final decision was reached by fusing those segmented images. Two fusion algorithms, Majority Voting and Dempster-Shafer, were considered. The former takes the consensus from the most voted class per pixel. In Dempster-Shafer fusion, for a pixel to be labeled as class $\mathrm{Ai}$, its belief function bel(Ai), estimated from the confusion matrix following the Equations (3) to (6), must be the greatest among other class labels.

\subsubsection{Accuracy Assessment}

To devise a suitable guideline for adopting the proposed scheme, the accuracy of water segmentations, based on the water indices and height and curvature features obtained from the Majority Voting and the Dempster-Shafer methods, were compared. The accuracies were assessed in terms of water surface areas and the class labels assigned to individual pixels. The interpretations reported were based on validating these observations against manual digitization of aerial photographs and field verification.

\subsubsection{Flooded Areas Extraction}

For flood monitoring and verification, the results were validated against Landsat images, similar to that of river extraction but based on the image acquired when the flood occurred. A similar water indices-based verification was performed, providing the extracted water surfaces of both rivers and flooded areas. Change detection was subsequently needed to subtract these surfaces from those of rivers, from images obtained from prior to the flood. In this study, flood monitoring and verification was implemented on Google Earth Engine (GEE). The application displayed the flooded areas in the four studied areas.

\section{Results}

As an initial assessment, to illustrate the merit of MMI-based threshold optimization, the scatter plots of the two water indices, MNDWI and NDWI2, were compared (Figure 4). After determining the water bodies, the cut-off values of these indices were typically set to zero (Figure 4a). A large proportion of pixels at the NDWI2 lower end extend over the entire range of MNDWI, whose water discrimination was not definitive, as shown by the horizontal stripe. On the other hand, should the optimal values, which for MNDWI was greater than 0.032 and for NDWI2, greater than 0.016 , 
be employed (Figure 4b), not only were those indecisive pixels eliminated, but the regression line of both indices also improved, with the coefficient of determination $\left(\mathrm{r}^{2}\right)$ increasing from 0.774 to 0.863 , and SSE (Sum of Squared Errors) dropping by 50\%.

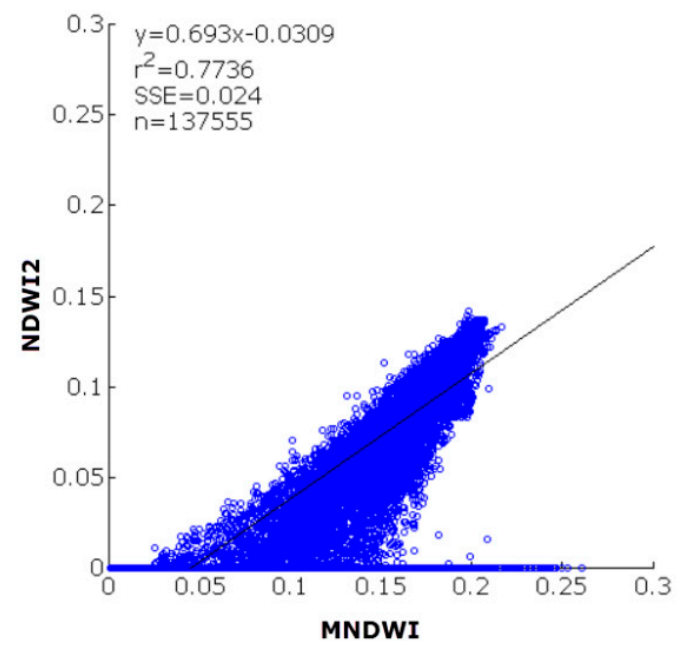

(a)

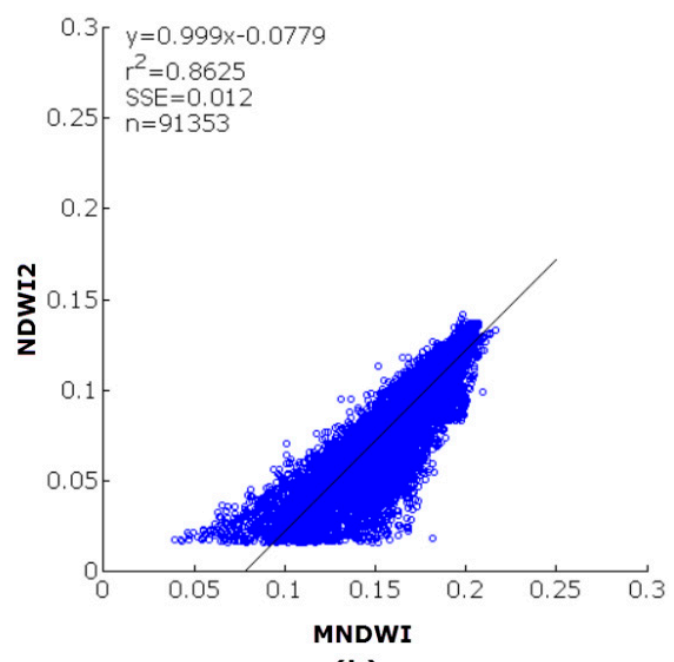

(b)

Figure 4. The scatter plots showing the correlation between MNDWI and NDWI2 when using: (a) the typical zero threshold; and (b) the optimal threshold, which are MNDWI > 0.032 and NDWI2 > 0.016 .

We argue that differences between empirical and optimal thresholds were only marginal and can be neglected in most practical settings. Moreover, small variations in the thresholds did not significantly alter the overall appearance of the extraction. Upon closer inspection, the preliminary study revealed that even a slight shift in the prescribed indices could cause under- or over-segmentation of the finer hydrological details, such as canal branches, due to the ambiguous boundary. Accordingly, this made the existing index based scheme prone to significant subjective inter- and intra-observer variability, as well as being regionally dependent.

For these studied areas, the optimal thresholds and their respective directions that maximized the MMI were as follows: NDWI2 $>0.016$, MDNWI $>0.032$, LSD of Height $<1.6^{-8}$, and LSD of Curvature $>1.6^{-8}$. Due to numerical approximation in practice, $0 \mathrm{~s}$ may be assigned to LSDs. Once the optimal thresholds were determined, the segmented binary images of thematic layers were fused by using the Majority Voting and Dempster-Shafer methods.

The effectiveness of the proposed scheme was then visually assessed. Figure 5 depicts extractions of four images in Pathumthani at different timeframes, from 2013 to 2015, by means of Majority Voting (Figure 5a) and Dempster-Shafer (Figure 5b) fusions. Due to a consistent MMI objective and DSM's ability to preserve diminutive structures, Dempster-Shafer was able to delineate water bodies very accurately, while also maintaining their branching and finer details. Due to limited space, only the extractions using Dempster-Shafer in 2013 are illustrated for the remaining areas (Figure 5c,d). 


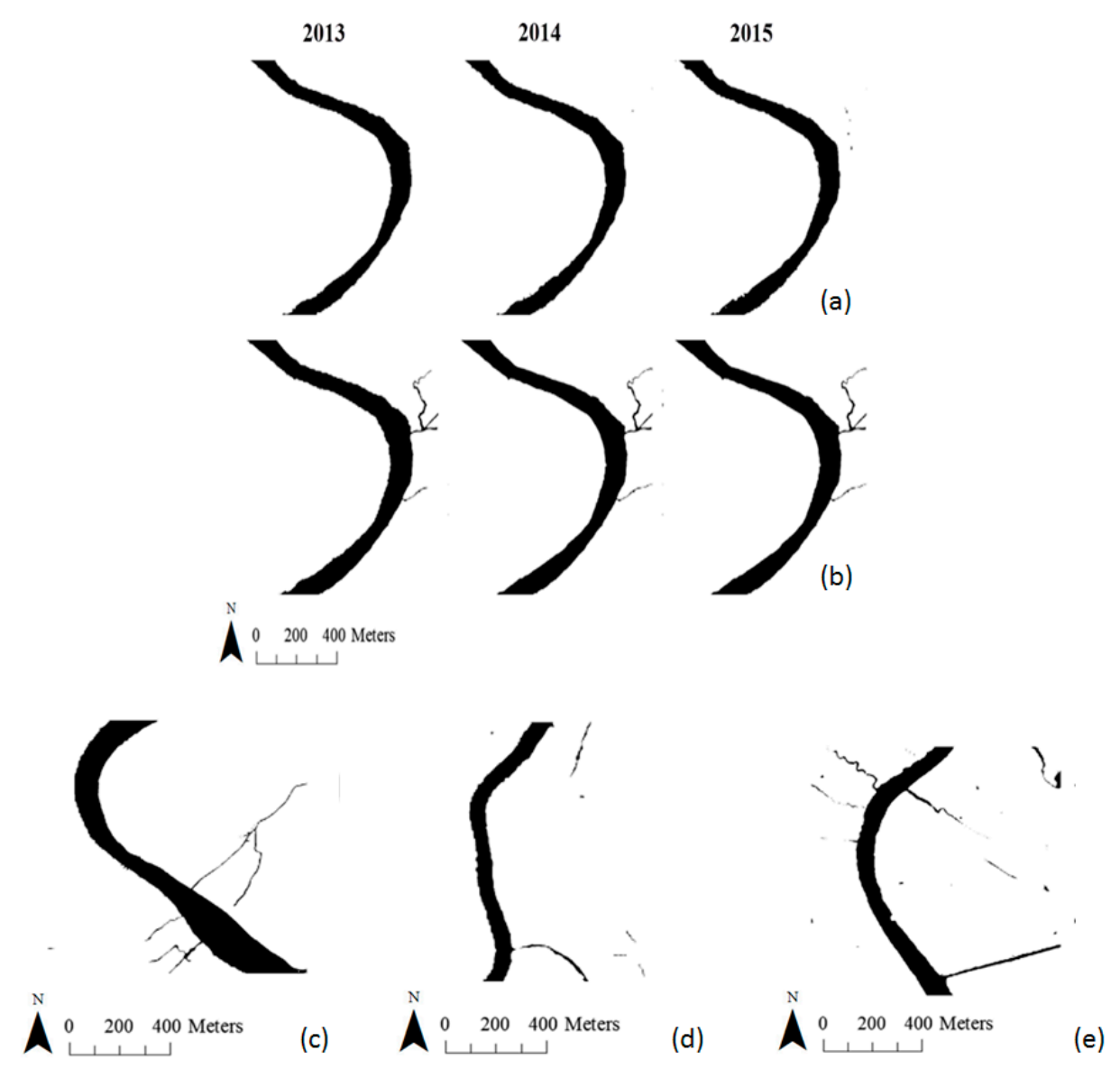

Figure 5. Water extraction results in Pathumthani for image one in 2013 to 2015 using: (a) Majority Voting; and (b) Dempster-Shafer. (c) Image two. (d) Image three; and (e) image four obtained in 2013 by Dempster-Shafer.

The numerical evaluation shown in Table 3 also confirms our visual observation. In this table, Pathum-1 to -4 correspond to images a (or b), c, d, and e in Figure 5, respectively. Therein, the two fusion methods were compared with respect to their accuracy, precision, recall, and F-measure. For all considered areas and corresponding extractions at one-year intervals (2013, 2014, and 2015), the Dempster-Shafer method provided the highest averaged accuracy of $98.25 \%$, while that of Majority Voting was $97.21 \%$. This trend is manifested in the other assessments. Dempster-Shafer outperformed Majority Voting in terms of precision and F-measure, with values of $93.09 \%$ versus $75.44 \%$, and $91.87 \%$ versus $84.91 \%$, respectively. In these experiments, the recall, which is the ratio between total pixels predicted as water and those actually being water, of the Dempster-Shafer method was, on average, lower than its counterparts. The reason for this is due to having high false negative rate, which occurs when water pixels are disregarded as non-water. This relatively low sensitivity was expected if Bayesian inferences of a proposition (being water), whose count were small compared to the contradicting classes, were taken into account.

Figure 6 shows the correlation between the ground truth data, which were manual delineations by experts, and automatic water extractions obtained from the Dempster-Shafer and Majority Voting fusions. The Dempster-Shafer results are more highly correlated to the ground truth than those of Majority Voting.

Unlike Pathumthani, other cities are not as flat, and thus few outliers existed with non-zero but small topographic variations that, together with water indices, had made the majority of votes false positives. These outliers, however, had less confidence, and were accordingly removed by 
Dempster-Shafer. Notably, although Majority Voting was sensitive to noise in these datasets, the proposed method worked equally well with both flat and non-flat areas.

Table 3. Numerical assessment of Landsat with DSM fusion with four variables, including water indices and surface properties, with MMI-optimized thresholding.

\begin{tabular}{|c|c|c|c|c|c|c|c|c|}
\hline \multirow{3}{*}{ Dataset } & \multicolumn{8}{|c|}{ Data Fusion } \\
\hline & \multicolumn{4}{|c|}{ Majority Voting } & \multicolumn{4}{|c|}{ Dempster-Shafer } \\
\hline & Accuracy & Precision & Recall & F-Measure & Accuracy & Precision & Recall & F-Measure \\
\hline Pathum 1-2013 & 97.46 & 82.05 & 99.06 & 89.76 & 98.74 & 96.06 & 94.77 & 95.41 \\
\hline Pathum 1-2014 & 97.52 & 82.57 & 99.05 & 90.06 & 98.69 & 96.51 & 94.00 & 95.24 \\
\hline Pathum 1-2015 & 97.58 & 82.99 & 99.02 & 90.30 & 98.90 & 93.33 & 98.46 & 95.82 \\
\hline Pathum 2-2013 & 96.77 & 79.96 & 97.53 & 87.88 & 96.94 & 94.36 & 86.09 & 90.03 \\
\hline Pathum 2-2014 & 96.83 & 80.41 & 97.52 & 88.14 & 97.89 & 94.39 & 91.45 & 92.90 \\
\hline Pathum 2-2015 & 96.86 & 79.98 & 98.28 & 88.19 & 97.68 & 94.48 & 90.13 & 92.25 \\
\hline Pathum 3-2013 & 97.85 & 71.23 & 97.79 & 82.42 & 98.70 & 91.06 & 90.60 & 90.83 \\
\hline Pathum 3-2014 & 97.86 & 71.10 & 98.13 & 82.46 & 98.62 & 90.64 & 89.96 & 90.30 \\
\hline Pathum 3-2015 & 97.66 & 68.90 & 97.09 & 80.60 & 98.31 & 91.27 & 85.72 & 88.41 \\
\hline Pathum 4-2013 & 96.95 & 69.99 & 96.74 & 81.21 & 97.97 & 91.83 & 87.27 & 89.49 \\
\hline Pathum 4-2014 & 96.84 & 68.11 & 97.66 & 80.25 & 98.07 & 91.70 & 88.28 & 89.95 \\
\hline Pathum 4-2015 & 96.31 & 67.96 & 90.52 & 77.64 & 98.45 & 91.39 & 92.14 & 91.76 \\
\hline Avg. of Pathumthani & 97.21 & 75.44 & 97.37 & 84.91 & 98.25 & 93.09 & 90.74 & 91.87 \\
\hline Surat Thani & 97.85 & 99.65 & 98.15 & 98.89 & 97.91 & 99.70 & 98.16 & 98.93 \\
\hline Chumphon & 99.24 & 99.33 & 99.89 & 99.61 & 99.37 & 99.49 & 99.87 & 99.68 \\
\hline Nakhon Si Thammarat & 99.57 & 91.70 & 98.02 & 94.75 & 99.59 & 91.73 & 98.32 & 94.91 \\
\hline Avg. of Other Sites & 98.89 & 96.89 & 98.69 & 97.75 & 98.96 & 96.97 & 98.78 & 97.84 \\
\hline Total Avg. & 97.54 & 79.73 & 97.63 & 87.48 & 98.39 & 93.86 & 92.35 & 93.06 \\
\hline
\end{tabular}

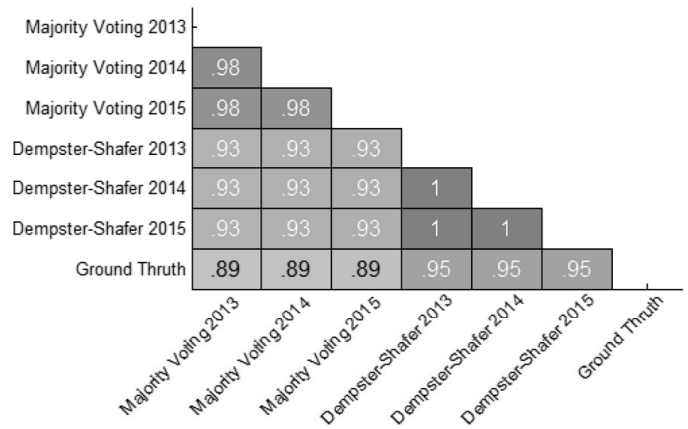

(a)

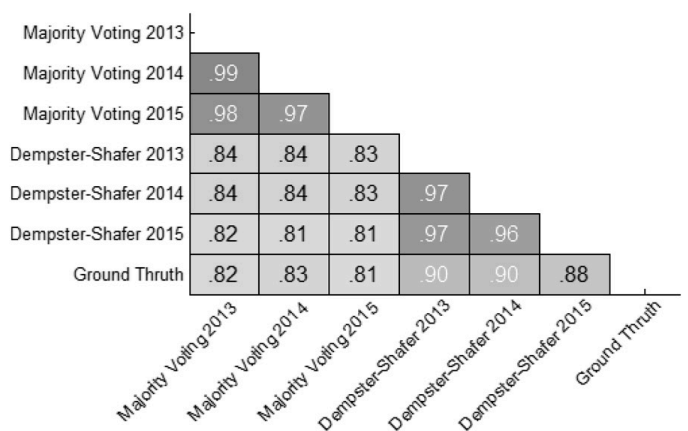

(c)

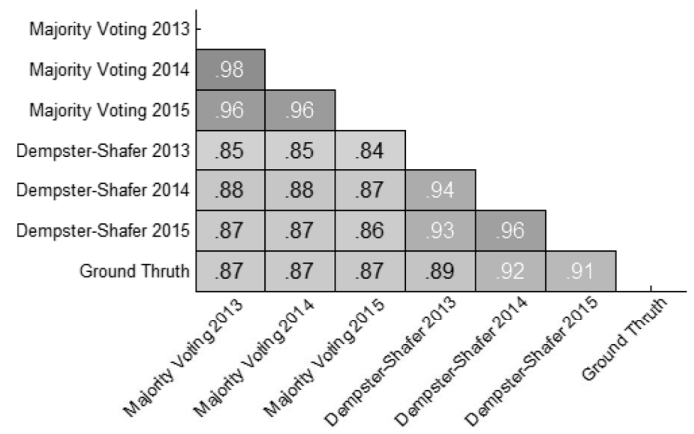

(b)

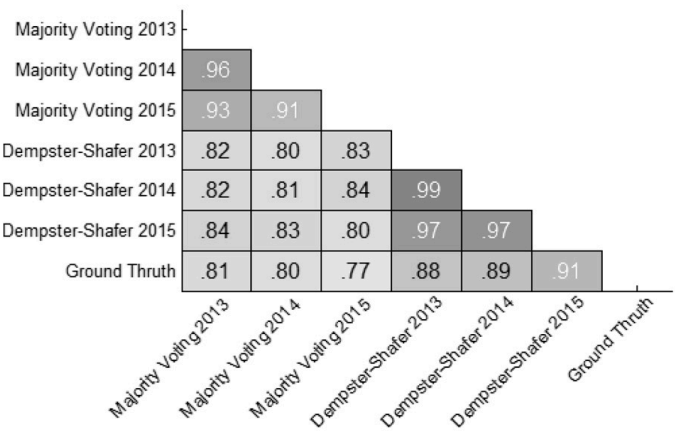

(d)

Figure 6. Correlation results of Pathumthani for image one (a), two (b), three (c), and four (d).

If DSM was just used for fusion but not incorporated during MMI optimization, only the MNDWI and NDWI2 indices would be mutually assessed for thresholding. The results of fused water extraction in Pathumtani during 2013, by using Equation (10) are given in Table 4. Disregarding surface attributes, the optimal threshold of these indices changed from NDWI2 >0.016 and MNDWI > 0.032 to NDWI2 > 
0.045 and MNDWI > 0.09. However, DSM, whose topographic thresholds were set to zero, was still used during the fusion. Accordingly, the averaged extraction accuracies for the respective samples were slightly improved, compared to those in Table 3 when Dempster-Shafer fusion was used. Specifically, the averaged accuracy, precision, recall, and F-measure increased from $98.09 \%$, $93.33 \%, 89.68 \%$, and $91.44 \%$ to $98.63 \%, 92.26 \%, 94.85 \%$, and $93.51 \%$, respectively. If the Majority Voting scheme was used instead, then the results deteriorated. Notably, the Dempster-Shafer fusion of the indices and DSM was generally accurate and independent of mutual threshold settings. Both twoand four-variable MMI provided similar results and the four-variable MMI performed equally well by using either of the fusions. Dempster-Shafer fusion with four-variable MMI optimization was therefore preferred. To ensure its generalization ability, the MMI-based thresholding and thematic layer fusion were applied in the other cities that had different climates, and resident and geographical characteristics, namely Chumphon, Surat Thani, and Nakhon Si Thammarat. The resultant extractions are illustrated in Figure 7 and their respective numerical assessments are listed in Table 3. These results are consistent with those of Pathumthani; Dempster-Shafer yielded more accurate extractions than its peer, with mean accuracy, precision, recall, and F-measure of $98.96 \%, 96.97 \%, 98.78 \%$, and $97.84 \%$, respectively.

Table 4. Numerical assessment of Landsat with DSM fusion with two-variable (water indices) MMI optimized thresholding.

\begin{tabular}{ccccccccc}
\hline \multirow{2}{*}{ Dataset } & \multicolumn{9}{c}{ Data Fusion } \\
\cline { 2 - 9 } & \multicolumn{9}{c}{ Majority Voting } & \multicolumn{3}{c}{ Dempster-Shafer } \\
\cline { 2 - 9 } & Accuracy & Precision & Recall & F-Measure & Accuracy & Precision & Recall & F-Measure \\
\hline Pathum 1-2013 & 96.60 & 76.32 & 98.31 & 85.93 & 98.89 & 93.33 & 98.46 & 95.82 \\
Pathum 2-2013 & 96.50 & 80.88 & 94.43 & 87.14 & 98.18 & 94.51 & 93.18 & 93.84 \\
Pathum 3-2013 & 97.77 & 71.50 & 95.96 & 81.94 & 98.98 & 89.79 & 95.57 & 92.59 \\
Pathum 4-2013 & 96.79 & 70.76 & 93.53 & 80.57 & 98.46 & 91.39 & 92.17 & 91.78 \\
Avg. & 96.92 & 74.87 & 95.56 & 83.90 & 98.63 & 92.26 & 94.85 & 93.51 \\
\hline
\end{tabular}

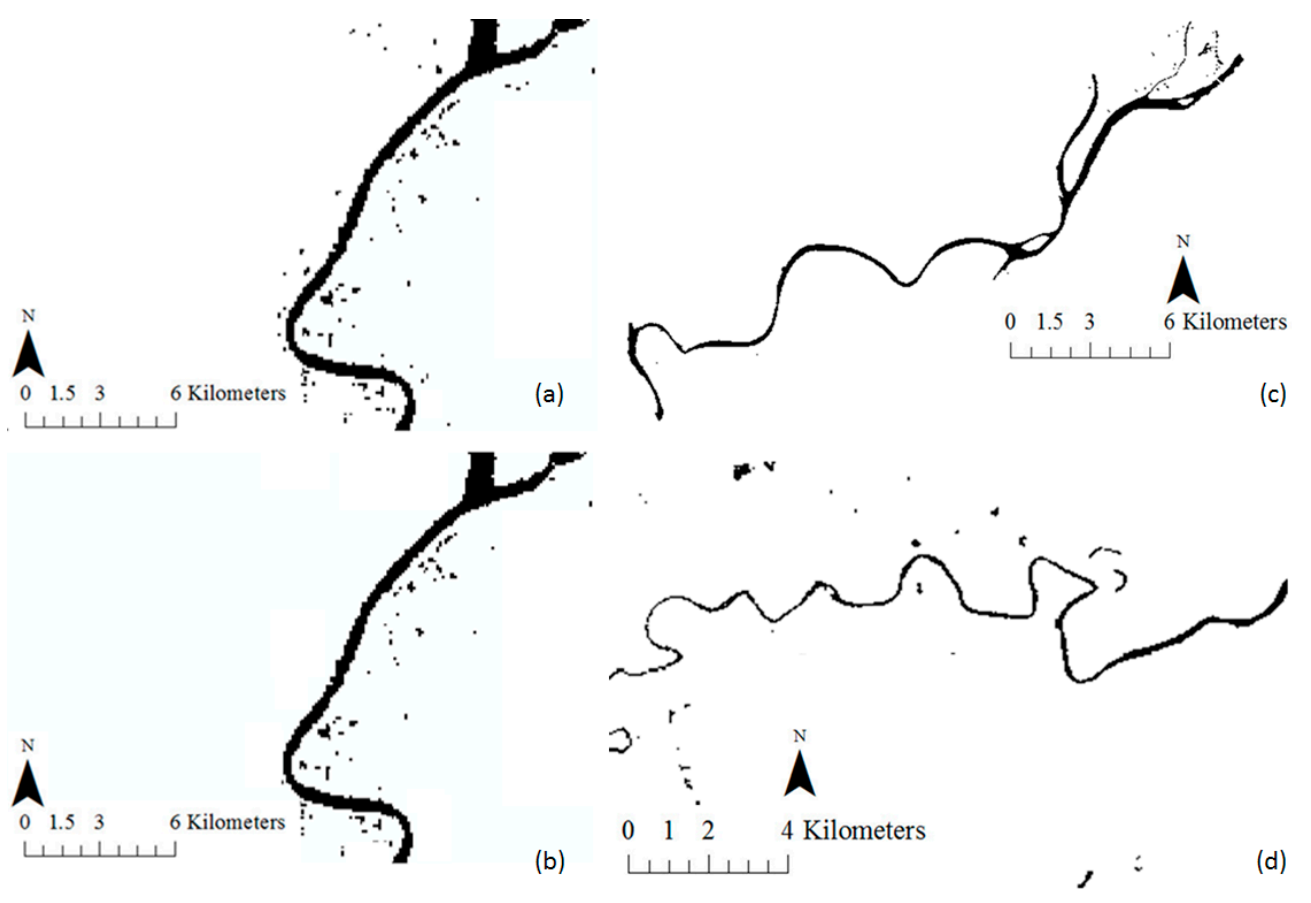

Figure 7. Water extraction results for the Pak Phanang River in Nakhon Si Thammarat) using: (a) Majority Voting; and (b) Dempster-Shafer. (c) The Tapi River in Surat Thani; and (d) the Lang Suan River in Chumphon using Dempster-Shafer. 
The averaged accuracy, precision, recall, and F-measure decreased from $97.26 \%, 75.81 \%, 97.78 \%$, and $85.34 \%$ to $96.92 \%, 74.87 \%, 95.56 \%$, and $83.9 \%$, respectively. The reason for these inconsistencies was because the surface information was neglected, so care must be taken when choosing the appropriate fusion strategy.

To demonstrate the potential for this technique to be applied to monitoring, a similar approach was used for the selected areas when the flooding occurred, from which their respective rivers were subtracted. The major flood incidents were reported in November 2011 for Pathumthani and in January 2017 for the remaining cities. The resultant overlaid flood maps are depicted in Figures 8-11, where the dark and light blue indicate the permanent water or river and temporary water, being the flooded areas, respectively. The orange arrows indicate the locations of extracted images in the inset.

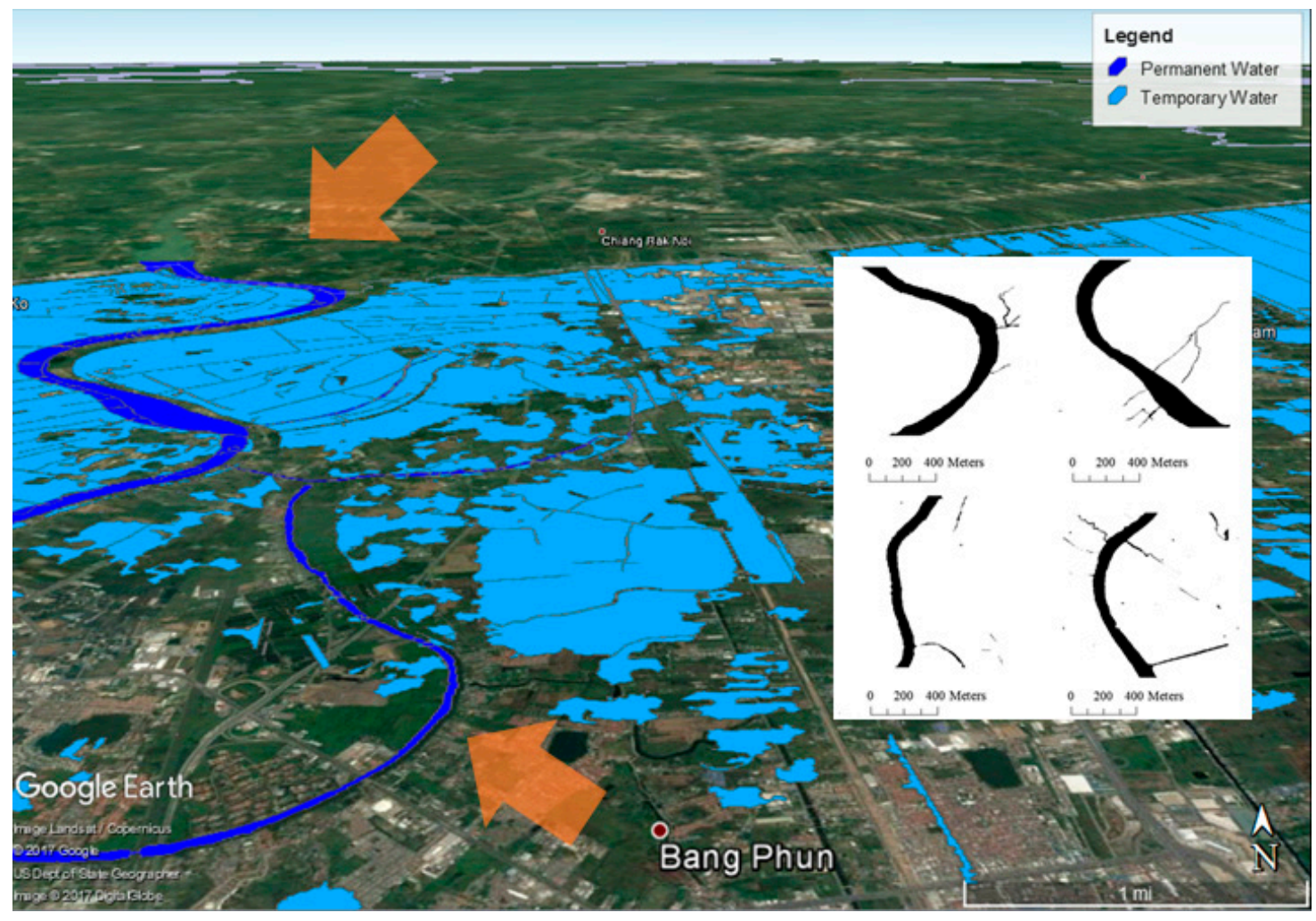

Figure 8. Discrimination between the Chaophraya River in dark blue and the flooded areas light blue in Pathumthani. 


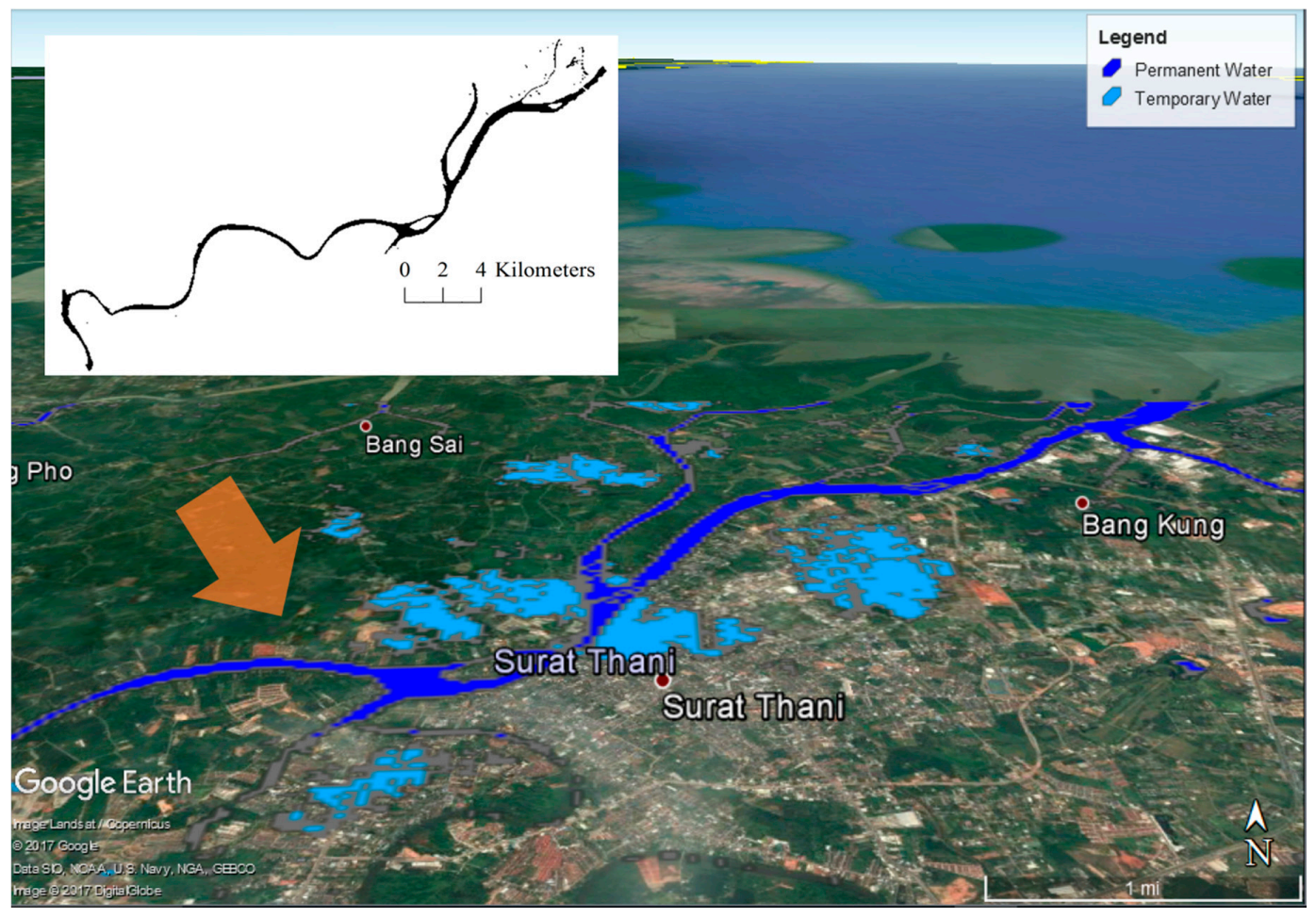

Figure 9. Discrimination between the Tapi River in dark blue and the flooded areas in light blue in the Muang district, Surat Thani.

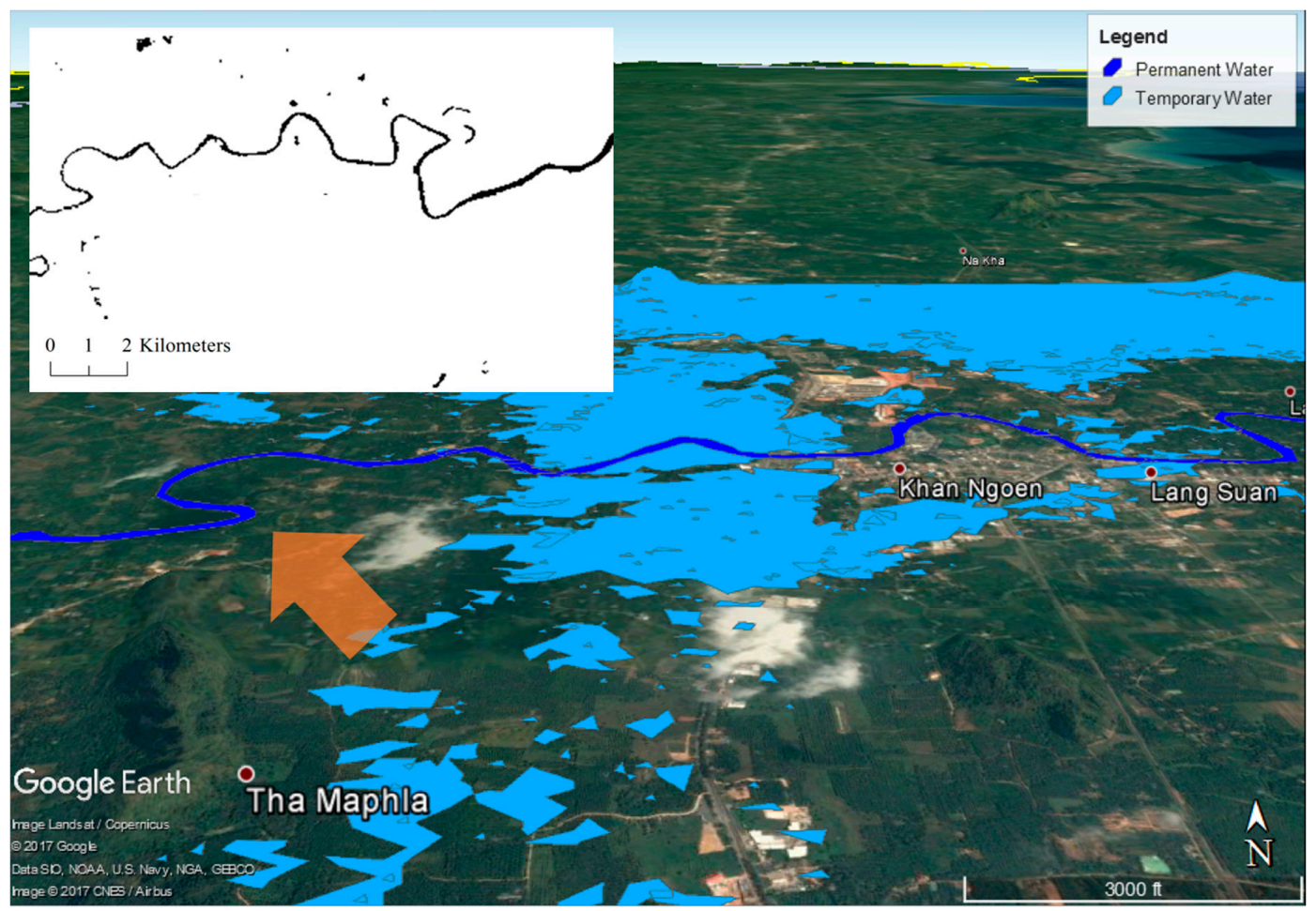

Figure 10. Discrimination between the Lang Suan River in dark blue and the flooded areas in light blue in the Lang Suan district, Chumphon. 


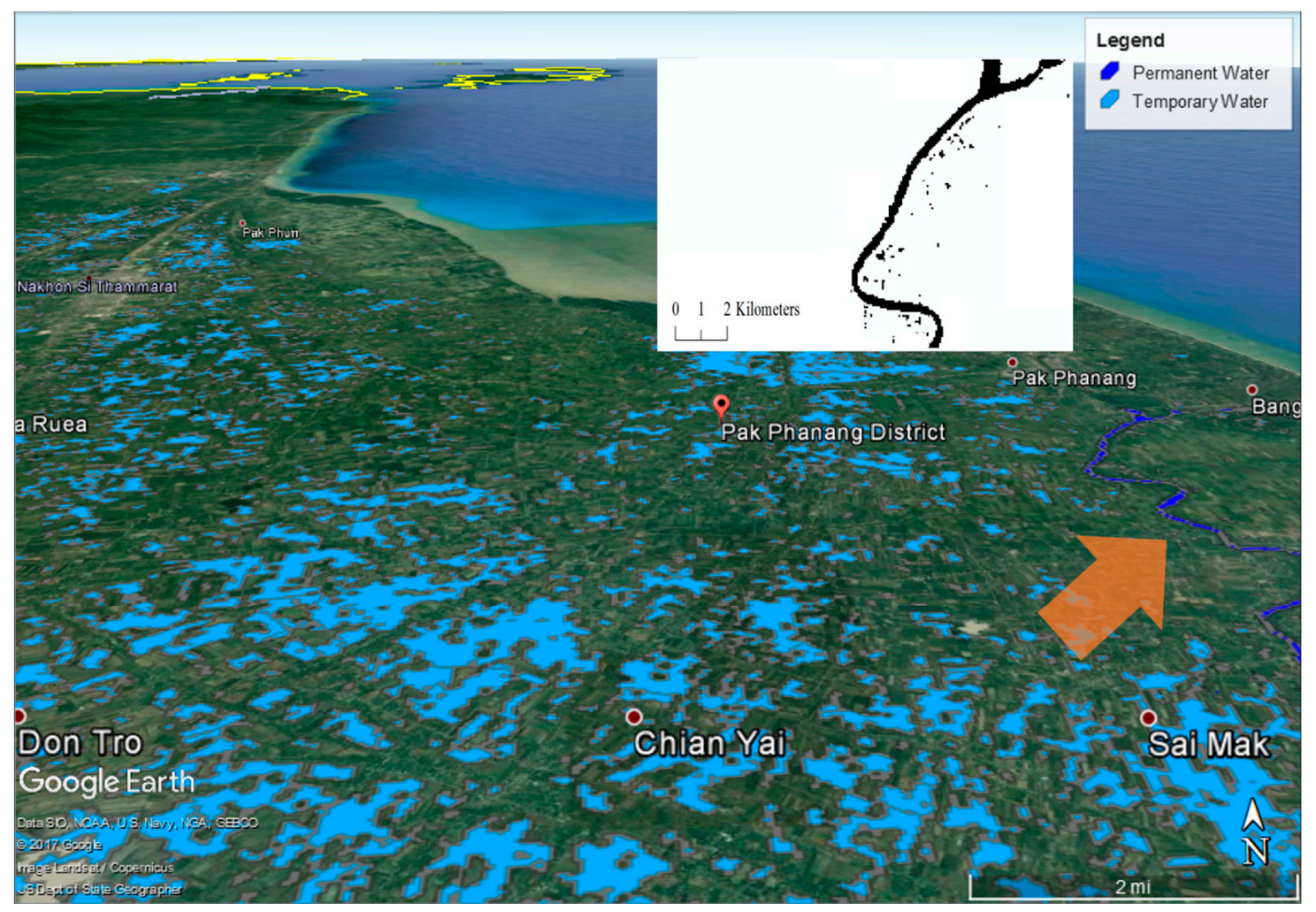

Figure 11. Discrimination between the Pak Phanang River, shown in dark blue, and the flooded areas, shown in light blue in the Pak Phanang district, Nakhon Si Thammarat.

With these maps, the authorities could devise well-informed rescue, mitigation, and evacuation plans and related management. Using Pathumthani as an example, the flooding was widespread but in small regions, divided by elevated local roads, and the flooding was equal on both sides of the Chaophraya River (Figure 8). A similar pattern was evident in Nakhon Si Thammarat, but the flooding was more severe to the west of the Pak Phanang River, as shown in Figure 10. The incident, however, was far more critical in Lang suan, Surat Thani, as the flooding covered more than 50 percent of the city (Figure 9), whereas that in the Muang district of the same city, it was less severe but mitigation was clearly needed in four villages around the river (Figure 11). These accurate discriminations could also help in determining the affected areas and preparing appropriate relief measures and resources, as well as planning infrastructure that can cope with reoccurrence and lessen the potential devastation, reducing the cost of relief efforts and rebuilding.

Although the Sentinel-2 images are of higher spatial resolution than the Landsat 8 images, the time frame of this study dated back to earlier than June 2015, when the Sentinel-2 was first launched. In addition, when a flood occurred at Pak Phanang in January 2017, the images of the area were extensively covered by cloud (Figure 12) which could have compromised the results. Furthermore, Yang et al. [24] reported that, for water classification, Sentinel-2 yielded comparable accuracy to Landsat 8 . The latter was therefore used for this study. Having said that, a future study could benefit from the higher spatial resolution of Sentinel-2, as its images are now available. 


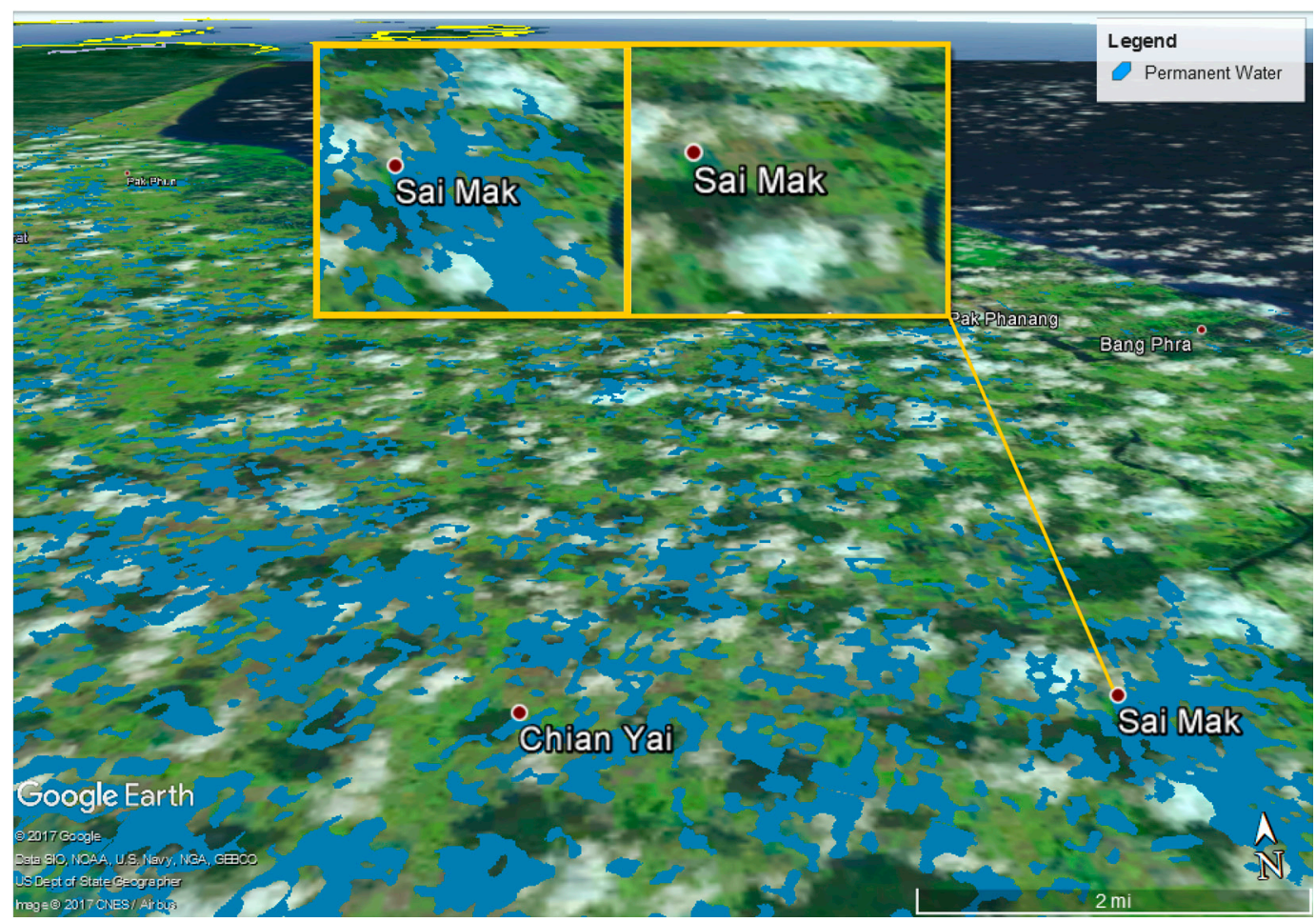

Figure 12. Discrimination between flooded areas in light blue (left inset) and the Sentinel-2 (right inset) image in Pak Phanang district, Nakhon Si Thammarat.

\section{Conclusions}

Classification based on indices was an effective means of water surface extraction from the Landsat images. The main drawback of Landsat images is its modest precision, being unable to extract narrower water bodies such as branching and canals. This study proposed an information theoretic-based framework for combining multiple contextual extractions, based on MMI and Dempster-Shafer fusion that not only produced consistent results but also preserved both salient and minute hydrological details. By augmenting spectral-rich Landsat images with fine surface data from DSM, the results exhibited more preferable characteristics, both visually and numerically, than traditional methods when validated with manual digitization. In addition, the proposed scheme did not require any expensive fine resolution satellite images, making the detailed segmentation more accessible. Moreover, this framework could be adopted in a change detection scheme for separating temporary from permanent water. The applications for our proposed framework include flood assessment and monitoring. Experiments on the cities that were selected had different characteristics, highlighting its potential for practical use in devising appropriate measures, as well as assisting administrative decision making.

This study proposed a prototype scheme for water surface extraction. A guideline was outlined for integrating information theoretic framework (MMI) with intermediate level computer vision to serve this task. The input data involved are the easily accessible and cost-effective Landsat images and DSM. The main emphasis was on accurately and precisely identifying standing water, so that it could be reliably used for subsequent temporal analyses. Water extraction has been demonstrated to lay a foundation for various hydrological studies, including flood simulation, erosion modeling, and landslides. We anticipate that more accurate and reliable delineation results obtained from this study could be readily and effectively used in preparation for future system integration, such as in conjunction with multi-temporal Landsat or MODIS data, for real-time flood monitoring. The temporality of Landsat data, for example, can be integrated to monitor changes, such as those caused by flooding. In the future, the proposed scheme could be integrated with real-time incident reports from flood victims, rescue teams, or relevant parties, so as to make the identification of flood areas more reliable 
and consistent with the actual incident. Technological convergence in computing could also help with an official flood mitigation and management regime.

Acknowledgments: This research project was financially supported by the Agricultural Research Development Agency Public Organization, National Research Council of Thailand, and Thailand Research Organizations Network. The authors would like to thank the Geo-Informatics and Space Technology Development Agency, Public Organization, Google Inc. and the USGS website for providing the remotely sensed data (Landsat) used in preparation of the paper.

Author Contributions: Paramate Horkaew and Supattra Puttinaovarat equally contributed to this work. Paramate Horkaew and Supattra Puttinaovarat conceived the research, analyzed the remotely sensed data, designed the fusion algorithm and the experiments, and summarized the findings. Paramate Horkaew and Supattra Puttinaovarat wrote the manuscript.

Conflicts of Interest: The authors declare no conflict of interest.

\section{References}

1. Kotera, A.; Nagano, T.; Hanittinan, P. Assessing the degree of flood damage to rice crops in the Chao Phraya delta, Thailand, using MODIS satellite imaging. Paddy Water Environ. 2016, 14, 271-280. [CrossRef]

2. Cho, S.Y.; Chang, H. Recent research approaches to urban flood vulnerability, 2006-2016. Nat. Hazards 2017, 88, 633-649. [CrossRef]

3. Li, L.; Vrieling, A.; Skidmore, A.; Wang, T.; Muñoz, A.R.; Turak, E. Evaluation of MODIS spectral indices for monitoring hydrological dynamics of a small, seasonally flooded wetland in Southern Spain. Wetlands 2015, 35, 851-864. [CrossRef]

4. Memon, A.A.; Muhammad, S.; Rahman, S.; Haq, M. Flood monitoring and damage assessment using water indices: A case study of Pakistan flood-2012. Egypt. J. Remote Sens. Space Sci. 2015, 18, 99-106. [CrossRef]

5. Mueller, N.; Lewis, A.; Roberts, D.; Ring, S.; Melrose, R.; Sixsmith, J.; Ip, A. Water observations from space: Mapping surface water from 25 years of Landsat imagery across Australia. Remote Sens. Environ. 2016, 174, 341-352. [CrossRef]

6. Schafer, M.L.; Lundstrom, J.O. Detection of temporary flooded areas with potential floodwater mosquito production using imaging radar. Int. J. Remote Sens. 2012, 33, 1943-1953. [CrossRef]

7. Yu, X.; He, H.; Hu, D.; Zhou, W. Land cover classification of remote sensing imagery based on interval-valued data fuzzy c-means algorithm. Sci. China Earth Sci. 2014, 57, 1306-1313. [CrossRef]

8. Suwanprasit, C.; Srichai, N. Impacts of spatial resolution on land cover classification. Proc. Asia-Pac. Adv. Netw. 2012, 33, 39-47. [CrossRef]

9. Pu, R.; Landry, S.; Yu, Q. Object-based urban detailed land cover classification with high spatial resolution IKONOS imagery. Int. J. Remote Sens. 2011, 32, 3285-3308. [CrossRef]

10. Carleer, A.; Wolff, E. The VHR data region-based classification possibilities in the framework of Control with Remote Sensing of European CAP. In Proceedings of the 31st International Symposium of Remote Sensing on Environment, Saint Petersburg, Russia, 20-24 June 2005; pp. 1-4.

11. Herold, M.; Gardner, M.; Roberts, D.A. Spectral resolution requirements for mapping urban areas. IEEE Trans. Geosci. Remote Sens. 2003, 41, 1907-1919. [CrossRef]

12. Roy, D.P.; Ju, J.; Mbow, C.; Frost, P.; Loveland, T. Accessing free Landsat data via the Internet: Africa's challenge. Remote Sens. Lett. 2010, 1, 111-117. [CrossRef]

13. Ju, J.; Roy, D.P. The availability of cloud-free Landsat ETM+ data over the conterminous United States and globally. Remote Sens. Environ. 2008, 112, 1196-1211. [CrossRef]

14. Erdogan, M.; Maras, H.H.; Yilmaz, A.; Ozerbil, O.T. Resolution merge of 1: 35000 scale aerial photographs with Landsat 7 ETM imagery. In Proceedings of the Archives Photogrammetry, Remote Sensing, and Spatial Information Sciences, Beijing, China, 3-11 July 2008; pp. 1281-1285.

15. Muad, A.M.; Foody, G.M. Super-resolution mapping of landscape objects from coarse spatial resolution imagery. Int. Soc. Photogramm. Remote Sens. 2010, 15, 79-91. [CrossRef]

16. Olmanson, L.G.; Brezonik, P.L.; Bauer, M.E. Evaluation of medium to low resolution satellite imagery for regional lake water quality assessments. Water Resour. Res. 2011, 47, 1-14. [CrossRef]

17. Feyisa, G.L.; Meilby, H.; Fensholt, R.; Proud, S.R. Automated water extraction index: A new technique for surface water mapping using Landsat imagery. Remote Sens. Environ. 2014, 140, 23-35. [CrossRef] 
18. Jiang, H.; Feng, M.; Zhu, Y.; Lu, N.; Huang, J.; Xiao, T. An Automated method for extracting rivers and lakes from Landsat imagery. Remote Sens. 2014, 6, 5067-5089. [CrossRef]

19. Wang, Y.; Huang, F.; Wei, Y. Water body extraction from LANDSAT ETM+ image using MNDWI and KT transformation. In Proceedings of the 21st International Conference on Geoinformatics, Kaifeng, China, 20-22 June 2013; pp. 1-5.

20. Chao, Z.; Sheng, M. Study on extraction methods for water information in Nantong city, China using Landsat ETM+ data. In Proceedings of the 2011 International Conference on Remote Sensing, Environment and Transportation Engineering (RSETE), Nanjing, China, 24-26 June 2011; pp. 771-774.

21. Shen, L.; Li, C. Water body extraction from Landsat ETM+ imagery using adaboost algorithm. In Proceedings of the 2010 18th International Conference on Geoinformatics, Beijing, China, 18-20 June 2010; pp. 1-4.

22. Horkaew, P.; Puttinaovarat, S.; Khaimook, K. River boundary delineation from remotely sensed imagery based on SVM and relaxation labeling of water index and DSM. J. Theor. Appl. Inf. Technol. 2015, 71, $376-386$.

23. Du, Y.; Zhang, Y.; Ling, F.; Wang, Q.; Li, W.; Li, X. Water bodies' mapping from Sentinel-2 imagery with modified normalized difference water index at $10-\mathrm{m}$ spatial resolution produced by sharpening the SWIR band. Remote Sens. 2016, 8, 354. [CrossRef]

24. Yang, X.; Zhao, S.; Qin, X.; Zhao, N.; Liang, L. Mapping of Urban Surface Water Bodies from Sentinel-2 MSI Imagery at $10 \mathrm{~m}$ Resolution via NDWI-Based Image Sharpening. Remote Sens. 2017, 9, 596. [CrossRef]

25. Zhou, Y.; Dong, J.; Xiao, X.; Xiao, T.; Yang, Z.; Zhao, G.; Qin, Y. Open Surface Water Mapping Algorithms: A Comparison of Water-Related Spectral Indices and Sensors. Water 2017, 9, 256. [CrossRef]

26. Kaplan, G.; Avdan, U. Object-based water body extraction model using Sentinel-2 satellite imagery. Eur. J. Remote Sens. 2017, 50, 137-143. [CrossRef]

27. Yu, H.Y.; Cheng, G.; Ge, X.S.; Lu, X.P. Object oriented land cover classification using ALS and GeoEye imagery over mining area. Trans. Nonferrous Met. Soc. China 2011, 21, s733-s737. [CrossRef]

28. Mason, D.C.; Giustarini, L.; Garcia-Pintado, J.; Cloke, H.L. Detection of flooded urban areas in high resolution Synthetic Aperture Radar images using double scattering. Int. J. Appl. Earth Obs. Geoinform. 2014, 28, 150-159. [CrossRef]

29. Gallant, J.C. Terrain analysis: Principles and applications; John Wiley \& Sons: Hoboken, NJ, USA, 2000.

30. Rokni, K.; Ahmad, A.; Selamat, A.; Hazini, S. Water feature extraction and change detection using multitemporal Landsat imagery. Remote Sens. 2014, 6, 4173-4189. [CrossRef]

31. Ashraf, M.; Nawaz, R.A. Comparison of change detection analyses using different band algebras for baraila wetland with Nasa's multi-temporal Landsat dataset. J. Geogr. Inf. Syst. 2015, 7, 1-19. [CrossRef]

32. Nguyen, D.D. Water body extraction from multi spectral image by spectral pattern analysis. In Proceedings of the ISPRS-International Archives of the Photogrammetry, Remote Sensing and Spatial Information Sciences, Melbourne, Australia, 25 August-1 September 2012; pp. 181-186.

33. Mcnally, A.J.; Mckenzie, S.J. Combining multispectral aerial imagery and digital surface models to extract urban buildings. J. Maps 2011, 7, 51-59. [CrossRef]

34. Lu, Y.H.; Trinder, J.C.; Kubik, K. Automatic building detection using the Dempster-Shafer algorithm. Photogramm. Eng. Remote Sens. 2006, 72, 395-403. [CrossRef]

35. Stal, C.; Tack, F.; De Maeyer, P.; De Wulf, A.; Goossens, R. Airborne photogrammetry and LIDAR for DSM extraction and 3D change detection over an urban area-A comparative study. Int. J. Remote Sens. 2013, 34, 1087-1110. [CrossRef]

36. Salehi, B.; Zhang, Y.; Zhong, M. Object-based land cover classification of urban areas using VHR imagery and photogrammetrically-derived DSM. In Proceedings of the ASPRS 2011 Annual Conference, Milwaukee, WI, USA, 1-5 May 2011; pp. 1-7.

37. Song, Y.S.; Sohn, H.G.; Park, C.H. Efficient water area classification using Radarsat-1 SAR imagery in a high relief mountainous environment. Photogramm. Eng. Remote Sens. 2007, 73, 285-296. [CrossRef]

38. Yorozuya, A.; Kamimera, H.; Okazumi, T.; Iwami, Y.; Kwak, Y. Estimation of water surface elevation on inundated area using satellite based information. In Proceedings of the MODSIM2013, 20th International Congress on Modelling and Simulation, Modelling and Simulation Society of Australia and New Zealand, Adelaide, Australia, 1-6 December 2013; pp. 2353-2359.

39. Wang, Z.Y.; Boesch, R.; Ginzler, C. Arial images and LiDAR fusion applied in forest boundary detection. In Proceedings of the 7th WSEAS International Conference on Signal, Speech and Image Processing, Beijing, China, 15-17 September 2007; pp. 130-135. 
40. Liu, J.K.; Hsiao, K.H.; Shih, P.T.Y. A geomorphological model for landslide detection using airborne LIDAR data. J. Mar. Sci. Technol. 2012, 20, 629-638. [CrossRef]

41. Hurst, M.D.; Mudd, S.M.; Walcott, R.; Attal, M.; Yoo, K. Using hilltop curvature to derive the spatial distribution of erosion rates. J. Geophys. Res. Earth Surface 2012, 117. [CrossRef]

42. Pirotti, F.; Tarolli, P. Suitability of LiDAR point density and derived landform curvature maps for channel network extraction. Hydrol. Process. 2010, 24, 1187-1197. [CrossRef]

43. Chabala, L.M.; Mulolwa, A.; Lungu, O. Landform classification for digital soil mapping in the Chongwe-Rufunsa area. Zambia Agric. For. Fish. 2013, 2, 156-160. [CrossRef]

44. Dragut, L.; Blaschke, T. Automated classification of landform elements using object-based image analysis. Geomorphology 2006, 81, 330-344. [CrossRef]

45. Li, W.; Du, Z.; Ling, F.; Zhou, D.; Wang, H.; Gui, Y.; Zhang, X. A comparison of land surface water mapping using the normalized difference water index from TM, ETM+ and ALI. Remote Sens. 2013, 5, 5530-5549. [CrossRef]

46. Gao, B.C. NDWI-a normalized difference water index for remote sensing of vegetation liquid water from space. Remote Sens. Environ. 1996, 58, 257-266. [CrossRef]

47. Silveira, M.; Heleno, S. Water/land segmentation in SAR images using level sets. In Proceedings of the 15th IEEE International Conference on Image Processing ICIP 2008, San Diego, CA, USA, 12-15 October 2008; pp. 1896-1899.

48. Margarida, S.; Sandra, H. Classification of water regions in SAR images using level sets and non-parametric density estimation. In Proceedings of the IEEE International Conference on Image Processing ICIP 2009, Cairo, Egypt, 7-10 November 2009; pp. 1685-1688.

49. Mcfeeters, S.K. The use of normalized difference water index (NDWI) in the delineation of open water features. Int. J. Remote Sens. 1996, 17, 1425-1432. [CrossRef]

50. Haibo, Y.; Zongmin, W.; Hongling, Z.; Yu, G. Water body extraction methods study based on RS and GIS. Procedia Environ. Sci. 2011, 10, 2619-2624. [CrossRef]

51. Qiao, C.; Luo, J.; Sheng, Y.; Shen, Z.; Zhu, Z.; Ming, D. An adaptive water extraction method from remote sensing image based on NDWI. J. Indian Soc. Remote Sens. 2012, 40, 421-433. [CrossRef]

52. $\mathrm{Xu}, \mathrm{H}$. Modification of normalised difference water index (NDWI) to enhance open water features in remotely sensed imagery. Int. J. Remote Sens. 2006, 27, 3025-3033. [CrossRef]

53. Lacaux, J.P.; Tourre, Y.M.; Vignolles, C.; Ndione, J.A.; Lafaye, M. Classification of ponds from high-spatial resolution remote sensing: Application to rift valley fever epidemics in Senegal. Remote Sens. Environ. 2007, 106, 66-74. [CrossRef]

54. Gardelle, J.; Hiernaux, P.; Kergoat, L.; Grippa, M. Less rain, more water in ponds: A remote sensing study of the dynamics of surface water from 1950 to present in pastoral Sahel (Gourma region, Mali). Hydrol. Earth Syst. Sci. 2010, 14, 309-324. [CrossRef]

55. Subramaniam, S.; Saxena, M. Automated algorithm for extraction of wetlands from IRS RESOURCESAT LISS III data. ISPRS-Int. Arch. Photogramm. Remote Sens. Spat. Inf. Sci. 2011, 193-198. [CrossRef]

56. Dambach, P.; Machault, V.; Lacaux, J.P.; Vignolles, C.; Sié, A.; Sauerborn, R. Utilization of combined remote sensing techniques to detect environmental variables influencing malaria vector densities in rural West Africa. Int. J. Health Geogr. 2012, 11, 1-12. [CrossRef] [PubMed]

57. Hui, F.; Xu, B.; Huang, H.; Yu, Q.; Gong, P. Modelling spatial-temporal change of Poyang lake using multitemporal Landsat imagery. Int. J. Remote Sens. 2008, 29, 5767-5784. [CrossRef]

58. Viola, P.; Wells, W.M., III. Alignment by maximization of mutual information. Int. J. Comput. Vis. 1997, 24, 137-154. [CrossRef]

59. Collignon, A.; Maes, F.; Delaere, D.; Vandermeulen, D.; Suetens, P.; Marchal, G. Automated multi-modality image registration based on information theory. In Information Processing in Medical Imaging; Kluwer: Norwell, MA, USA, 1995; pp. 263-274.

60. Qian, Y.; Li, M.; Wei, Q.; Ren, X. A Registration method for multimodal medical images using contours mutual information. Int. J. Adv. Res. Artif. Intell. (IJARAI) 2014, 3, 1-5. [CrossRef]

61. Loeckx, D.; Slagmolen, P.; Maes, F.; Vandermeulen, D.; Suetens, P. Nonrigid image registration using conditional mutual information. IEEE Trans. Med. Imaging 2010, 29, 19-29. [CrossRef] [PubMed]

62. Pluim, J.P.; Maintz, J.A.; Viergever, M.A. Mutual-information-based registration of medical images: A survey. IEEE Trans. Med. Imaging 2003, 22, 986-1004. [CrossRef] [PubMed] 
63. Wang, C.; Shi, A.; Wang, X.; Huang, F.; Liu, H. A novel registration method for high resolution remote sensing images based on JSEG and NMI. Comput. Sci. Inf. Syst. 2014, 12, 289-306. [CrossRef]

64. Suri, S.; Reinartz, P. Mutual-information-based registration of TerraSAR-X and Ikonos imagery in urban areas. IEEE Trans. Geosci. Remote Sens. 2010, 48, 939-949. [CrossRef]

65. Wang, B.; Wang, X.; Chen, Z. Spatial entropy based mutual information in hyperspectral band selection for supervised classification. Int. J. Numer. Anal. Model. Comput. Inf. 2009, 9, 181-192.

66. Suri, S.; Turmer, S.; Reinartz, P.; Stilla, U. Registration of high resolution SAR and optical satellite imagery in urban areas. In Proceedings of the ISPRS Hannover Workshop, Hannover, Germany, 2-5 June 2009; pp. 1-6.

67. Kern, J.P.; Pattichis, M.; Stearns, S.D. Registration of image cubes using multivariate mutual information. In Proceedings of the Conference Record of the Thirty-Seventh Asilomar Conference on Signals, Systems and Computers 2004, Pacific Grove, CA, USA, 9-12 November 2003; pp. 1645-1649.

68. Lee, J.; Kim, D.W. Feature selection for multi-label classification using multivariate mutual information. Pattern Recognit. Lett. 2013, 34, 349-357. [CrossRef]

69. Doquire, G.; Verleysen, M.A. Comparison of multivariate mutual information estimators for feature selection. In Proceedings of the ICPRAM, Algarve, Portugal, 6-8 February 2012; pp. 176-185.

70. Pillai, K.G.; Vatsavai, R.R. Multi-sensor Remote Sensing Image Change Detection: An Evaluation of similarity measures. In Proceedings of the 2013 IEEE 13th International Conference on Data Mining Workshops (ICDMW), Dallas, TX, USA, 7-10 December 2013; pp. 1053-1060.

71. Gueguen, L.; Pesaresi, M.; Ehrlich, D.; Lu, L. Urbanization analysis by mutual information based change detection between SPOT 5 panchromatic images. In Proceedings of the 2011 6th International Workshop on Analysis of Multi-Temporal Remote Sensing Images (Multi-Temp), Trento, Italy, 12-14 July 2011; pp. 157-160.

72. Jahari, M.; Khairunniza-Bejo, S.; Shariff, A.R.M.; Shafri, H.Z.M. Change detection studies in Matang mangrove forest area, Perak. Pertanika J. Sci. Technol. 2011, 19, 307-327.

73. Erten, E.; Rossi, C.; Hajnsek, I. Glacier surface monitoring by maximizing mutual information. ISPRS-Int. Arch. Photogramm. Remote Sens. Spat. Inf. Sci. 2012, 1, 41-44. [CrossRef]

74. Clark, G.W.; Ackerman, S.H.; Tillier, E.R.; Gatti, D.L. Multidimensional mutual information methods for the analysis of covariation in multiple sequence alignments. BMC Bioinform. 2014, 15, 1-12. [CrossRef] [PubMed]

75. Du, P.; Liu, S.; Gamba, P.; Tan, K.; Xia, J. Fusion of difference images for change detection over urban areas. IEEE J. Sel. Top. Appl. Earth Obs. Remote Sens. 2012, 5, 1076-1086. [CrossRef]

76. Jiang, D.; Zhuang, D.; Huang, Y.; Fu, J. Survey of multispectral image fusion techniques in remote sensing applications. Image Fusion Appl. InTech 2011, 1-22. [CrossRef]

77. Zhang, J. Multi-source remote sensing data fusion: Status and trends. Int. J. Image Data Fusion 2010, 1, 5-24. [CrossRef]

78. Licciardi, G.; Pacifici, F.; Tuia, D.; Prasad, S.; West, T.; Giacco, F.; Gamba, P. Decision fusion for the classification of hyperspectral data: Outcome of the 2008 GRS-S data fusion contest. IEEE Trans. Geosci. Remote Sens. 2009, 47, 3857-3865. [CrossRef]

79. He, M.; Xia, J. High-dimensional multispectral image fusion: Classification by neural network. In Proceedings of the Third International Asia-Pacific Environmental Remote Sensing of the Atmosphere, Ocean, Environment, and Space, Hangzhou, China, 23-27 October 2002; pp. 36-43.

80. Chu, H.T.; Ge, L. Combination of genetic algorithm and Dempster-Shafer theory of evidence for land cover classification using integration of SAR and optical satellite imagery. ISPRS-Int. Arch. Photogramm. Remote Sens. Spat. Inf. Sci. 2012, 1, 173-178. [CrossRef]

81. Trinder, J.; Salah, M. Aerial images and LiDAR data fusion for disaster change detection. ISPRS Ann. Photogramm. Remote Sens. Spat. Inf. Sci. 2012, 1, 227-232. [CrossRef]

82. Rashidi, A.; Ghassemian, H. Extended Dempster-Shafer theory for multi-system/sensor decision fusion. In Proceedings of the Commission IV Joint Workshop on Challenges in Geospatial Analysis, Integration and Visualization II, Stuttgart, Germany, 8-9 September 2003; pp. 31-37.

83. Lam, L.; Suen, C.Y. Application of majority voting to pattern recognition: An analysis of its behavior and performance. Systems, Man and Cybernetics, Part A: Systems and Humans. IEEE Trans. 1997, 27, 553-568. [CrossRef] 
84. Laanaya, H.; Martin, A.; Aboutajdine, D.; Khenchaf, A. Classifier fusion for post-classification of textured images. In Proceedings of the 2008 11th International Conference on Information Fusion, Cologne, Germany, 30 June-3 July 2008; pp. 1-7.

85. Dempster, A.P. A generalization of Bayesian inference. J. R. Statist. Soc. 1968, 32, 202-247. [CrossRef]

86. Shafer, G. A Mathematical Theory of Evidence; Princeton University Press: Princeton, NJ, USA, 1997.

87. Zeverbergen, L.W.; Thorne, C.R. Quantitative Analysis of Land Surface Topography. Earth Surface Process. Landf. 1987, 12, 47-56. [CrossRef]

(C) 2017 by the authors. Licensee MDPI, Basel, Switzerland. This article is an open access article distributed under the terms and conditions of the Creative Commons Attribution (CC BY) license (http://creativecommons.org/licenses/by/4.0/). 